\title{
Conclusions of the Ad-hoc Review Committee (ARC) on the International Commission on Stratigraphy (ICS) of the International Union of Geological Sciences (IUGS) (Paris, 7-8 November 2005)
}

\section{Background}

Following the recommendations of the IUGS Strategic Planning Committee (2000) and IUGS Strategic Action Plan (2001) to appoint Ad-hoc Review Committees (ARCs) to hold reviews of all IUGS-funded scientific activities on a regular basis, the IUGS Executive Committee decided at its last meeting in Vilnius, Lithuania (March 2005) that an ARC should be convened to review the IUGS International Commission on Stratigraphy (ICS). ICS has been part of IUGS since 1965, and the last review of ICS by the IUGS was in 1995.

The importance of achieving international consensus on stratigraphic matters, such as those on stratigraphic classification and terminology, has been clear to the geological community since the 1st International Geological Congress (IGC) in Paris in 1878, when the Commission for Unification of Geological Nomenclature, a direct predecessor of ICS, was established. One important product of ICS activities is the International Stratigraphic Guide (1976, 1994, 1999), which has been translated into different languages and whose recommendations concerning stratigraphic classification, terminology, and procedure are widely accepted throughout the world and followed in most national and regional codes on stratigraphy. Following the creation within ICS in 1960 of Subcommissions on individual geological systems, one of the most important activities of the ICS became the standardization of Global Stratotype Sections and Points (GSSPs), popularly known as "golden spikes", for the systems and their subdivisions down to the level of stages. The first of them was thus introduced in 1972 to define the basal StageLochkovian - and hence the base of the whole of the Devonian System, at Klonk, in the Czech Republic.

Through such achievements it has always been clear to IUGS that the activities of ICS are among the most important within IUGS, and that they have rendered, and will continue to render, essential services for the international geological community.

\section{ARC participants}

The ARC members appointed by the IUGS Executive Committee (EC) were: Alberto Riccardi (IUGS EC member, Argentina, Chair), Zhang Hongren (IUGS President, China), John Callomon (external expert, England), Lucy Edwards (external expert, USA) and Gian Battista Vai (external expert, Italy). The ARC decided to interview the Chairs of ICS and some of its Subcommissions, selected in order to obtain an overview of ICS activities on the different geological eras, taking into account the practical consideration of their proximity to the meeting location.
They were: Felix Gradstein (ICS Chair, Norway), Maria Bianca Cita (ISSC-International Subcommission on Stratigraphic Classification - Chair, Italy), Phil Gibbard (ISQS - International Subcommission on Quaternary Stratigraphy-Chair, UK), T. Becker (ISDS - International Subcommission on Devonian Stratigraphy, Chair, Germany), and N. Morton (ISJS - International Subcommission on Jurassic Stratigraphy-Chair, UK), plus Fritz Hilgen (ISNS - International Subcommission on Neogene Stratigraphy-Chair, The Netherlands) invited at the request of the ICS Chair.

The meeting was held in Paris on 7, 8 November, 2005, and was attended by all the ARC members and the ICS officers, except for T. Becker and N. Morton, who were unable to attend but sent written reports. Relevant information for the meeting included: IUGS Statutes and Bye-laws; ICS Statutes; ICS Annual Reports for 2000-2004; the Report of the last ICS Review, 1995 , and additional documentation requested: (i) from F. Gradstein, on the overall aims and objectives of ICS, its structure and working procedures, on its main accomplishments over the last years, and on its planned future activities; and (ii) from M.B. Cita, P. Gibbard, F. Hilgen, T. Becker, and N. Morton, on the work of their Subcommissions during the last few years, and how this work has been integrated into that of the ICS.

During the ARC meeting separate interviews were held with the ICS officers. The main issues for discussion were: structure, working procedures, principal accomplishments and planned activities of ICS and its Subcommissions.

\section{Meeting highlights}

Some highlights of accomplishment were reviewed and selected prospects for the next four years were then outlined by the ICS officers. Important items mentioned during the meeting were:

1) that there is a need for a new, updated, expanded and more user-friendly edition of the International Stratigraphic Guide; it should be multi-authored, concise, well illustrated both digitally and interactively as necessary, and have examples of simple and complex applications;

2) that most of the Phanerozoic Stage GSSPs should aim to be defined in time for the International Geological Congress in 2008;

3) that the content of the time-scale GTS-2008 should be greatly expanded, to reflect the role of cyclostratigraphy based on orbital 'tuning', as well as planetary and archaeological timescales; 
4) that GSSPs, instead of GSSAs (Global Standard Stratigraphic Ages), will be defined for the Precambrian;

5) that there is now a need for chronostratigraphic standards at much finer levels of time-resolution than those of stages;

6) that in view of the fact that, as things stand, once all the Stage GSSPs are defined, ICS will not receive further support from IUGS; it is clear that some other organization will be needed to replace it, e.g. an International Association of Stratigraphic Geologists, although some would view that as a separate entity;

7) that some kind of Bureau of Standards will also be needed, to record and monitor the taxonomy and nomenclature of named stratigraphic units, a successor perhaps to the ICS's Lexique Stratigraphique International, and including then also the association of GSSPs with the management of Geoparks;

8) that there could be expected to arise a natural merging of adjacent Subcommissions with new mandates, including the formalization of finer intra-Stage chronostratigraphic subdivisions;

9) that a Special Projects Section is necessary, to communicate and collaborate with industry and national geological institutions;

10) that, in view of its increasing importance, there is need for strong, continuing support of the ICS website; the current volume of downloading of the new Geological Time Scale is truly remarkable;

11) that, contrary to statements in the ICS 2003 Annual Report, ICS does not maintain contacts with National Stratigraphic Committees;

12) that there were errors of omission in publications by the President and Secretary of ICS (2004), including the book The Geological Time Scale 2004, publications which, although products of their personal authorship, did not include any disclaimer to the effect that they were not official publications of ICS and IUGS, even though some of them did include the ICS and/or IUGS logos;

13) that there is a perceived absence of detailed discussion, among the Chairs of different ICS Subcommissions of the proposed GSSPs put forward by individual Subcommissions, resulting in some lack of overall cohesion in underlying principles and methods;

14) that ICS needs to become more open, democratic and evenhanded in its operation and decision-making;

15) that a possible way of improving ICS's organization and procedures could be through a working structure that makes ICS more directly responsible to an identifiable individual or body, e.g. a supervising body of National and/or Regional Representatives;

16) that ICS must not only serve, but also be seen to serve, the geological community as a whole.

\section{ARC Conclusions}

Following a discussion of the items summarized above, the ARC considered that ICS was to be congratulated for the important work it had done in promoting stratigraphic research. The establishment of GSSPs has made important worldwide contributions to the improvement of stratigraphy as a science. It also agreed that there is a strong continuing need for an international body of stratigraphers to stabilize stratigraphic procedure and terminology as the science of stratigraphy continues to develop new concepts and techniques. New Guides will be needed and will need to be amended; existing GSSPs will be challenged; the formal recognition of subdivisions below Stage is desirable; also, new techniques and new terminologies will emerge.

Finally, the ARC arrived at several conclusions. These were divided into proposed Actions, that are mainly concerned with procedural matters and that once approved by the IUGS Executive Committee become mandatory, and proposed Recommendations, which go beyond procedures and are not mandatory. These conclusions were circulated to the interviewed ICS Officers for comment. Received comments were incorporated in the final report. This was then submitted to the IUGS Executive Committee, which approved it at its annual EC meeting in January 2006 held at Punta Arenas, Chile. A list of proposed concrete actions to be taken by ICS was then sent by the IUGS Executive Committee in June 2006 to the ICS Executive. Some additional clarifications were added at the request of the ICS in September 2006.

The final list of Actions and Recommendations reads as follows:

\section{Actions}

a. All definitions on the ICS International Stratigraphic Chart not formally approved by IUGS should be regarded as having no official status.

b. IUGS to establish a standing Advisory Committee on Stratigraphy or Stratigraphic Standards, consisting of three experts, to advise it on all stratigraphic matters, including those submitted to it by ICS for consideration and to ensure the fulfillment of all legal procedural requirements of IUGS rules and procedures governing the establishment of international standards.

c. ICS to introduce changes in its Statutes, within the next six months, with regard to the election of Chair and Vice Chair, as follows:

- The Nominating Committee for election of Officers of ICS should consist of a maximum of five members, which shall include neither members of the Executive Committee of ICS nor Chairs of the Subcommissions of ICS;

- Members of the Nominating Committee should be proposed and elected by the Chairs of the ICS Subcommissions;

- The Nominating Committee for election of ICS Officers should propose not more than three candidates for each position;

- The ICS Officers are then elected by the Chairs of the ICS Subcommissions;

- The whole process of electing the Nominating Committee and the ICS Officers shall be conducted by the Chair of one of the ICS Subcommissions. As for the time-lines for selection of the Nominating Committee and ICS officers, they should comply, as in previous elections, with the schedules of IUGS, i.e. the final slate of elected officers should reach the IUGS EC at a set date before the ordinary session of the Council.

d. All ICS official publications must be formally approved by the IUGS EC to ensure compliance with constitutional requirements but not as an endorsement of their scientific or technical content. This Action applies primarily to all official publications in which ICS sets out formal changes expected to be followed by the international earth sciences community, such as, standards, procedural rules and the like, e.g. changes in the International Stratigraphic Chart, International Stratigraphical Guide, Statutes, etc.

e. All ICS official publications, i.e. those bearing the ICS logo, should be published according to the Statutes of IUGS and 
ICS, and conform to the provisions of the International Stratigraphic Guide. Regarding publications and the ICS logo, the first responsibility is clarity: can the reader tell whether the opinions expressed are those of the author personally, of the ICS Executive, of the voting members of the ICS, or of the IUGS Executive, etc.? If there are changes of technical wording, such as, for example, the omission of "Quaternary" or significant changes in its meaning, do these changes have the sanction of ICS and IUGS? Thus, websites and newsletters bearing the ICS/IUGS logos do not require explicit IUGS EC approval as such but any articles published in them should be explicit in the attribution of opinions and decisions to their sources. Books written by authors who also hold acknowledged positions in the ICS or IUGS should clearly state as appropriate what has been officially ratified and what has not, and should not bear either ICS or IUGS logos. Journal publications advocating ICS or IUGS action should be reviewed for procedural compliance prior to submission for publication.

f. The International Stratigraphic Guide should include procedural provisions for future amendments.

g. New editions of the International Stratigraphic Guide should be produced by the International Subcommission on Stratigraphic Classification of ICS (ISSC), in consultation with National and/or Regional Committees/Commissions on Stratigraphy. This could proceed in three steps: a) ISSC produces a draft of the Guide; b) ISSC consults National and/or Regional Committees; c) ISSC decides on the final version.

\section{Recommendations}

a. New editions of the International Stratigraphic Guide (ISG) should be built on previous editions, but begin with clear definitions of stratigraphic principles and go on to include concise explanations of new concepts, techniques and improvements in practical applications;

b. The ISG should be what the title implies, a Guide, and not be regarded as a mandatory edict of ICS under its parent body, IUGS;

c. ICS should try to make the ISG compatible as far as possible with existing National or Regional Codes (e.g. the North American Stratigraphic Code, NASC);

d. Classifications should be standardized at and above a certain stated hierarchical level; e. Typological definitions of standard chronostratigraphic units by means of boundary stratotypes, such as Stage GSSPs, should be extended downwards, below the Stage level in the hierarchy;

f. The ways in which standard boundary stratotypes are defined are practical matters that may vary from system to system and involve different criteria and techniques. They should therefore not be closely defined or regulated by ICS. This recommendation does not necessarily imply changes in the current ICS procedures for definition of GSSPs. It only stresses the importance of the criteria mentioned, as methods and techniques do not necessarily have the same significance in all systems;

g. The validity of parallel standard chronostratigraphic classifications, based on different practical geochronometric techniques, should be recognized. All standard classifications should be individually defined typologically in terms of boundary stratotypes, as is the current practice in Stage GSSPs. The recommendation on this item stresses the variability in the precision of stratigraphic resolution and correlations achievable by different techniques and in different systems, which should be fully exploited in practice and given formal expression;

h. If and when several parallel standard chronostratigraphic classifications have been produced, they should be compared and intercalibrated. One of them should then be selected to be the Primary Standard, others to be designated Secondary or Auxiliary Standards. This recommendation stresses the fact that when different parallel standard classifications are compared and intercalibrated, there is usually one that is superior because of its greater independence and precision;

i. Descriptions of GSSPs should include clear specifications of all the elements used in their definitions and their applicability;

j. Definitions of GSSPs should not be constrained by a deadline for completion, as such a deadline can be unrealistic, because of the essentially voluntary nature of the contributions of the contributors; such deadlines may hinder the attempt to arrive at sound, unforced and stable proposals;

$\mathrm{k}$. The function of ICS in this respect, as in others, should be reactive-guiding, unifying, codifying what has been achieved and encouraging what has been suggested, certainly - rather than proactive, trying to generate new initiative that it is unable to resource directly itself. 